\section{Temporary placement of a fully covered self- expanding metal stent to allow therapeutic ERCP}

A 64-year-old man with a previous history of laryngectomy followed by chemoand radiotherapy was referred to us in January 2014 because of dysphagia. Endoscopy detected a 4-cm-long benignappearing stricture in the hypopharynx (diameter $7 \mathrm{~mm}$ ) and a 6-cm-long malignant circumferential lesion in the midesophagus (diameter $8 \mathrm{~mm}$ ).

The patient was judged to be unfit for surgery, and therefore a fully covered self-expandable metal stent (FC-SEMS), $180 \times 80 \mathrm{~mm}$, was placed. Through-thescope balloon dilation (CRE 10-11$12 \mathrm{~mm}$; Microvasive, Boston Scientific Co., Natick, Massachusetts, United States) of the hypopharyngeal stricture was performed.

In February 2014 the patient developed a relapse of the hypopharyngeal stricture and jaundice due to compression of the common bile duct by the lymph nodes. Through-the-scope dilation of the stricture was performed, and a $14 \times$ $16 \times 100 \mathrm{~mm}$ FC-SEMS (Conio-Niti-S: Taewoong Medical, Seoul, Korea) was placed. The stent was removed 48 hours later immediately before therapeutic endoscopic retrograde cholangiopancreatography (ERCP). The duodenoscope could be easily inserted through the hypo- pharyngeal stricture, and ERCP revealed a $3-\mathrm{cm}$ stricture (diameter $1 \mathrm{~mm}$ ) of the common bile duct. A $60 \times 10-\mathrm{mm}$ biliary SEMS was placed at the biliary stricture. Refractory hypopharyngeal stenosis is the most frequent long-term complication after laryngectomy followed by radiotherapy $[1,2]$. A stricture in the proximal esophagus occurs in $10 \%-58 \%$ of these patients [3]. Introduction of a dedicated and effective hypopharyngeal removable SEMS has changed the endoscopic therapy of these patients [4]. In this case, it enabled the endoscopic palliation of a biliary stricture, by allowing for the passage of the duodenoscope through a previously severely stenosed esophagus ( $\bullet$ Video $\mathbf{1}$ ).

\section{Video 1}

Temporary placement of a fully covered, selfexpandable, metal stent at an esophageal stricture enabled passage of the duodenoscope for therapeutic endoscopic retrograde cholangiopancreatography.

Endoscopy_UCTN_Code_TTT_1AR_2AK

Competing interests: None
Benedetto Mangiavillano ${ }^{1}$, Deborah A. Fisher ${ }^{2}$, Massimo Conio ${ }^{1}$

${ }^{1}$ Gastroenterology and Gastrointestinal Endoscopy, General Hospital, Sanremo, Italy

${ }^{2}$ Division of Gastroenterology, Durham Veterans Affairs Medical Center, Duke University, Durham, North Carolina, United States

\section{References}

1 Jalisi M, Jalisi S. Advanced laryngeal carcinoma: surgical and non-surgical management options. Otolaryngol Clin North Am 2005; 38: 47-57

2 Nguyen NP, Moltz CC, Frank C et al. Severity and duration of chronic dysphagia following treatment for head and neck cancer. Anticancer Res 2005; 25: 2929-2934

3 Kronenberger MB, Meyers AD. Dysphagia following head and neck cancer surgery. Dysphagia 1994; 9: 236-244

4 Conio M, Blanchi S, Filiberti $R$ et al. A modified self-expanding Niti-S stent for the management of benign hypopharyngeal strictures. Gastrointest Endosc 2007; 65: $714-$ 720

Bibliography

DOI http://dx.doi.org/

10.1055/s-0034-1377440

Endoscopy 2014; 46: E419

(C) Georg Thieme Verlag KG

Stuttgart · New York

ISSN 0013-726X

Corresponding author

Benedetto Mangiavillano, MD

Gastroenterology and Gastrointestinal Endoscopy Borea Hospital

Via Giovanni Borea ${ }^{\circ} 56$

18038 - Sanremo (IM)

Italy

b_mangiavillano@hotmail.com 